\title{
Hydroxyurea-induced onychomadesis in a dog with chronic myeloid leukemia: A case report
}

\author{
Denner Santos dos Anjos ${ }^{\mathrm{a}, \mathrm{b}}$, Paula Barbosa Costa ${ }^{\mathrm{a}}$, Larissa Fernandes Magalhães ${ }^{\mathrm{a}}$, \\ Oscar Rodrigo Sierra ${ }^{\mathrm{b}}$, Sabryna Gouveia Calazans ${ }^{\mathrm{a}, 1}$, Carlos Eduardo Fonseca-Alves ${ }^{\mathrm{c}, 1 *}$
}

\author{
Keywords: \\ Canine \\ Hydroxycarbamide \\ Onycholysis \\ ${ }^{a}$ Veterinary Teaching Hospital, Department of \\ Veterinary Science, Franca University \\ (UNIFRAN), Franca, SP, Brazil \\ ${ }^{b}$ Veterinary Teaching Hospital, Department of \\ Veterinary Science, FCAV-UNESP, Jaboticabal, \\ SP, Brazil. \\ ${ }^{c}$ School of Veterinary Medicine and Animal \\ Science, Department of Veterinary Clinic, São \\ Paulo State University-UNESP, Botucatu, SP, \\ Brazil
}

\begin{abstract}
A B S T R A C T
A 12-year-old Rottweiler dog was presented with a history of prostration, weight loss and hyporexia for six months. Based on complete blood tests (hematological and biochemical analyses), bone marrow examination and imaging analysis, a diagnosis of chronic myeloid leukemia was made. Treatment with hydroxyurea at a dosage of $18 \mathrm{mg} / \mathrm{kg}$ twice daily was not effective in controlling the high count of white blood cells. Furthermore, after 35 days of hydroxyurea treatment, the animal developed onycholysis, with sloughing of the claws of the left pelvic and left thoracic limbs and exposure of the distal phalanx. Interruption of the medication was implemented, with clinical healing of the ungual lesions observed three months after initiation of the drug. White blood cells returned to normal after using cyclophosphamide. Currently, the animal is in complete remission, having a disease-free interval of 575 days without chemotherapy. To the authors' knowledge, this is the first report of hydroxyurea-induced onycholysis within a short-term period in a dog diagnosed with chronic myeloid leukemia.
\end{abstract}

(c) 2018 Elsevier Inc. All rights reserved.

\section{Background}

Hydroxyurea is a ribonucleotide reductase inhibitor that leads to decreased DNA synthesis in the $S$ phase of the cell cycle, resulting in cell death. ${ }^{1}$ In veterinary medicine, its clinical use covers a variety of tumor-related disorders including bone marrow disorders such as chronic granulocytic leukemia, polycythemia vera, essential thrombocythemia and hypereosinophilic syndrome; $;^{2-6}$ mast cell tumors ${ }^{7}$ and meningiomas. ${ }^{8}$ In human patients, hydroxyurea can be used to treat sickle-cell disease, melanoma, chronic myelogenous leukemia, ovarian tumor, squamous cell carcinoma of the head and neck, renal carcinoma, bladder urothelial carcinoma, prostate carcinoma and carcinoma of the uterine cervix. ${ }^{9}$

Although hydroxyurea is usually tolerable, this drug has a low margin of safety, with myelosuppression being the most common dose-limiting side effect in human and animal patients. ${ }^{10,11}$ Anemia is the most commonly observed side effect in dogs, with delay of growth, arrest of spermatogenesis and hepatic/splenic hemosiderosis being additional common side effects. ${ }^{11}$ Severe pneumonitis is also observed in humans. ${ }^{14}$

Mucocutaneous manifestations such as xerosis, diffuse cutaneous hyperpigmentation, pseudo-dermatomyositis lesions, stomatitis and nail changes (nail peeling, melanonychia, onycholysis/onychomadesis), although rare, have been observed after long use of therapy in human patients and dogs. ${ }^{1,12,13}$ The aim of this report is to describe a case of a dog with chronic myeloid leukemia that developed onycholysis secondary to treatment with hydroxyurea.

\footnotetext{
* Corresponding author.

E-mail address: carlos.e.alves@unesp.br (C.E. Fonseca-Alves).

${ }^{1}$ Both authors contributed equally.
}

\section{Case presentation}

A 12-year-old intact female Rottweiler dog weighing $28 \mathrm{~kg}$ was referred to the Veterinary Teaching Hospital with history of prostration, weight loss and hyporexia for six months. On physical exam, physiological parameters were within the normal ranges, with no fever. Analysis of hematological parameters revealed normocytic normochromic anemia, leukocytosis with left shift $(80,800 / \mu \mathrm{L}$; neutrophils: $75,952 / \mu \mathrm{L}$, band neutrophils: $1,616 / \mu \mathrm{L})$, thrombocytosis $\left(541 \times 10^{3} / \mu \mathrm{L}\right)$ and hypoalbuminemia $(1.4 \mathrm{~g} / \mathrm{dL})$, without biochemical changes in alanine aminotransferase, alkaline phosphatase, urea and creatinine as well as no alterations in urinalysis. Three-view thoracic radiographic study and abdominal ultrasound did not reveal any abnormalities. Doppler echocardiogram and electrocardiogram values were also within normal reference values. A rapid immunochromatographic test was performed for distemper (Immunoassay kit for rapid and qualitative detection of CDV antigen, Alere ${ }^{\circledR}$ S.A., São Paulo, SP, Brazil) and ehrlichiosis (Immunocomb ${ }^{\circledR}$ canine ehrlichia antibody IgG test, VP diagnostic, São Paulo, SP, Brazil), which yielded negative results. Based on the hematological parameters and above-described results, an occult infection was suspected, and enrofloxacin $(5 \mathrm{mg} / \mathrm{kg}$, PO, SID for one week) was prescribed. After one week, the subject continued presenting the same clinical manifestations. Another blood test was performed, which also revealed normocytic normochromic anemia, leukocytosis with left shift $(67,000 / \mu \mathrm{L}$; neutrophils: 58,960/ $\mu \mathrm{L}$, band neutrophils: $2680 / \mu \mathrm{L})$, eosinophilia $(2680 / \mu \mathrm{L})$ and thrombocytosis $\left(662 \times 10^{3} / \mu \mathrm{L}\right)$.

In view of these results, bone marrow analysis was performed, which revealed an increased myeloid: erythroid ratio (10:1), a moderate increase in mature granulocytes and megakaryocytes and a mild decrease of erythrocytic cells, with all cell lines showing normal morphology. The diagnosis was granulocytic and megakaryocytic hyperplasia. Based on these results and after excluding possible inflammatory/infection reactions, a diagnosis 
of chronic myeloid leukemia (chronic neutrophilic leukemia) was made.

Hydroxyurea was prescribed at a dosage of $18 \mathrm{mg} / \mathrm{kg}$ PO twice daily along with prednisone at a dosage of $1 \mathrm{mg} / \mathrm{kg}$ PO once daily. After 35 days on this therapy, the animal was returned to the Veterinary Teaching Hospital because of prostration and lameness. On physical exam, the dog presented exposure of the distal phalanx and nail loss on the left thoracic and pelvic limbs (Fig. 1). On complete blood count, a worsened level of anemia was detected (erythrocytes $3.0 \times 106$; RR: 5.5 to $8.5 \times 106$; hematocrit $26 \%$; RR: 37 to $55 \%$; hemoglobin $7.8 \mathrm{~g} / \mathrm{dL}$; RR: 12 to $18 \mathrm{~g} / \mathrm{dL}$ ), with anemia being macrocytic (mean corpuscular volume: $86.7 \mathrm{fl}$; RR: $60-77 \mathrm{fl}$ ) and hypochromic (30\%; RR: 31-36), and leukocytosis $\left(56,700 / \mu \mathrm{L}\right.$; RR: $6.0-18.0 \times 10^{3} /$ $\mu \mathrm{L}$; neutrophil: $53,865 / \mu \mathrm{L}$; RR: $\left.3.6-13.8 \times 10^{3} / \mu \mathrm{L}\right)$ and thrombocytosis $\left(701 \times 10^{3} / \mu \mathrm{L}\right.$; RR: 180 to $\left.400 \times 10^{3} / \mu \mathrm{L}\right)$ were observed (Table 1$)$.

Regarding dermatological side effects in chemotherapy, onycholysis and pain are classified as grade IV according to the Veterinary Cooperative Oncology Group. ${ }^{15}$ Despite the exposure of the distal phalanx in the claws, the animal presented grade IV cutaneous toxicity, associated with complete loss of claws and pain. Pain was assessed based on clinical examination and clinical history. Lameness was evident, and vocalization was evoked when the foot was palpated, with no history of trauma. Pain was likely elicited because of the exposure of the distal phalanx in the claws.

Based on the dermatological toxicity, chemotherapy was replaced with chlorambucil at a dosage of $6 \mathrm{mg} / \mathrm{m}^{2} \mathrm{PO}$ once daily. However, after 10 days, the animal presented with prostration and anorexia and a significantly high number of mature neutrophils on complete blood count

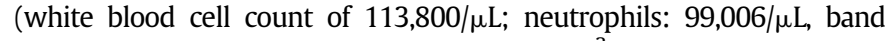
neutrophils: $7966 / \mu \mathrm{L}$; thrombocytosis $731 \times 10^{3} / \mu \mathrm{L}$ ) (Table 1 ). Because of these findings, chlorambucil was replaced with cyclophosphamide at a dosage of $300 \mathrm{mg} / \mathrm{m}^{2}$ once every 21 days for one year. After one week of cyclophosphamide treatment, the patient was lethargic and hyporexic, but severe decreases in the total number of leukocytes $(5400 / \mu \mathrm{L})$ and neutrophils $(5076 / \mu \mathrm{L})$ were observed (Table 1$)$.

Because of its clinical state, the dog was hospitalized for one day for maintenance fluid therapy using Lactate Ringer plus B complex. After three days, the owner related that the animal was active, with normal appetite and stepping on left limbs better than before. Onycholysis remained until 28 days after suspension of hydroxyurea and involved six claws in total (pelvic and thoracic left limbs). After three months of hydroxyurea suspension, the dog had no lameness and presented complete nail recovery (Fig. 2). Normal hematologic parameters have been found since the cessation of cyclophosphamide treatment, which lasted for one year. After the cessation of cyclophosphamide treatment, no chemotherapy was performed for six months, and currently, the patient is in complete remission at 575 days after diagnosis.

Chronic myelogenous leukemia is best managed with chemotherapy to control cell proliferation. Hydroxyurea is typically administered for this condition at a dosage of 20 to $25 \mathrm{mg} / \mathrm{kg}$ twice daily. In the present case, the dog was prescribed hydroxyurea at $18 \mathrm{mg} / \mathrm{kg}$ twice daily, as each capsule contained $500 \mathrm{mg}$. As the dog weighed $28 \mathrm{~kg}$, it would have needed a dose of $540 \mathrm{mg}$ (at $20 \mathrm{mg} / \mathrm{kg}$, as initially suggested by other authors ${ }^{16}$ ). However, as it is possible to reduce the dose by $50 \%$ after normalizing the neutrophil blood count, we prescribed a dosage of $18 \mathrm{mg} / \mathrm{kg}$ twice daily ( $36 \mathrm{mg} / \mathrm{kg}$ once daily) to avoid the need for capsule manipulation.

Hydroxyurea is well tolerated in dogs, even at dosage of $50 \mathrm{mg} /$ kg SID for 28 days. This was demonstrated by Morton et al., ${ }^{17}$ who observed decreases in the values of red blood cells, hemoglobin, hematocrit, white blood cells, neutrophils, monocytes, basophils and platelets 28 days after initiation of treatment with hydroxyurea relative to the values at diagnosis. Some of these abnormalities were observed in this study, such as decreases in red blood cells, hemoglobin, hematocrit and platelets, after 35 days of hydroxyurea treatment. However, this medication was not effective in decreasing the count of white blood cells, which increased after treatment $(29,500 /$ $\mu \mathrm{L}$ vs. $56,700 / \mu \mathrm{L}$ ). In addition, the presence of macrocytosis similar megaloblastic-like changes in anemia as appropriate commonly observed in hematological disorders due to myelodysplastic disorders as leukemia ${ }^{18,19}$ was observed, which was reversed after treatment with cyclophosphamide. One study evaluated 467 human patients with myeloid chronic leukemia and found that 270 (57\%) of the patients presented anemia, of which 119 (44\%) presented macrocytosis. $^{20}$

The mechanism of action of hydroxyurea in the bone marrow is well known, but its etiopathogeny regarding dermatological toxicity is poorly understood. One possible mechanism might involve its antiproliferative and cytostatic action in the epithelium. ${ }^{13,21}$ One study evaluated the ultrastructure of cutaneous abnormalities induced after prolonged use of hydroxyurea in three patients who developed severe generalized cutaneous atrophy and revealed abnormalities in the basal lamina and microfibrils in the papillary dermis. ${ }^{22}$

Although dermatological toxicity induced by hydroxyurea has been described in human patients and dogs after prolonged use, ${ }^{1,17,21}$ this case report describes the development of onycholysis after five weeks of use.

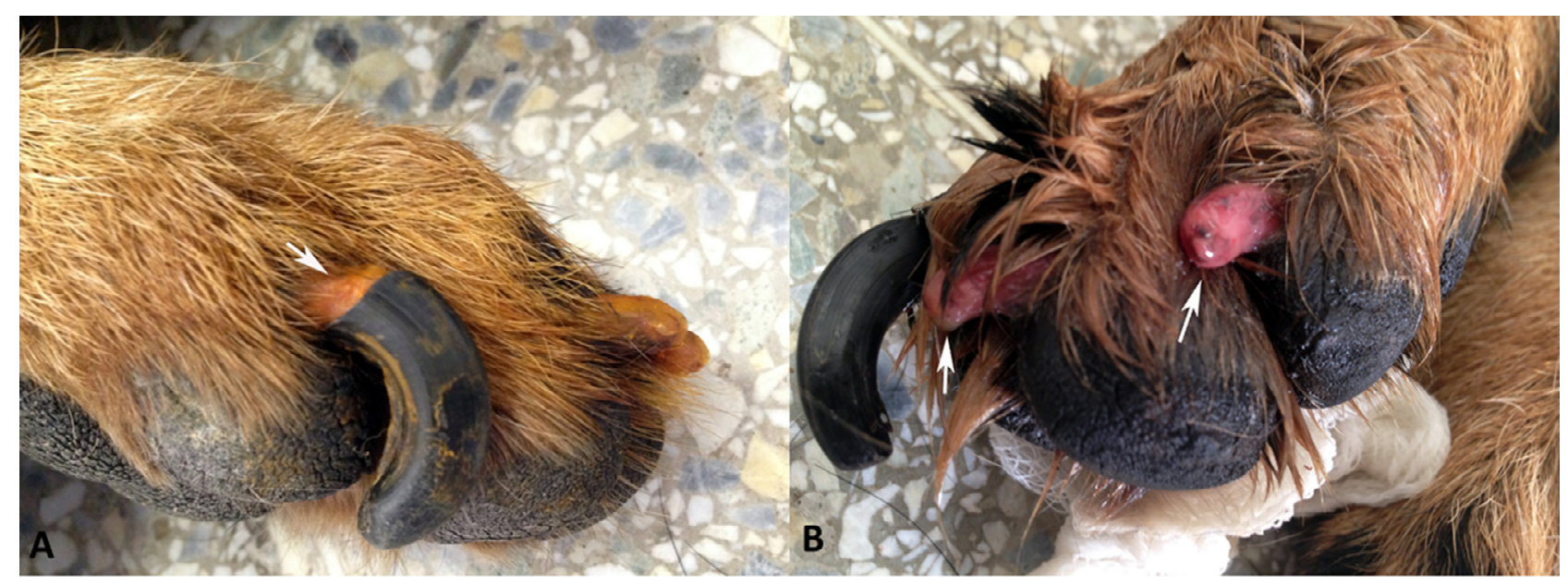

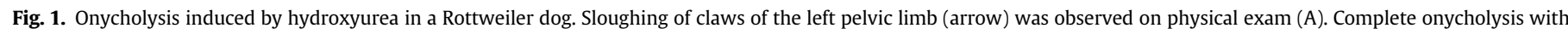
exposure of the distal phalanx of the left thoracic limb (arrows) (B). 
Table 1. Hematological and biochemical changes during treatment of myeloid chronic leukemia.

\begin{tabular}{llllllll}
\hline Parameters & D0 & D35 $^{* *}$ & D45*** & D52 & D59 & D147 & Reference values \\
\hline Red blood cell & 4.90 & 3.0 & 3.2 & 3.1 & 4.3 & 5.7 & $5.6-8.0$ \\
Hematocrit & 31.0 & 26.0 & 27.0 & 25.0 & 33.0 & 35.0 & $37-55$ \\
Hemoglobin & 10.50 & 7.80 & 8.6 & 8.1 & 10.6 & 11.7 & $14-19$ \\
VCM & 63,30 & 86.70 & 84.4 & 80.7 & 76.8 & 61.5 & $65-75$ \\
CHCM & 33,90 & 30.0 & 31.9 & 32.4 & 32.2 & 33.5 & $33-36$ \\
Platelets & 957,000 & 701,000 & 731,000 & 250,000 & 740,000 & 336,000 & $150-400 \times 10^{3}$ \\
WBC & 29,500 & 56,700 & 113,800 & 5400 & 16,000 & 16,200 & $6000-13000$ \\
Band neutrophils & 590 & 567 & 7966 & 0 & 160 & 162 & Rare \\
Neutrophils & 24,780 & 53,865 & 99,006 & 5076 & 14,400 & 14,418 & $3000-10500$ \\
Lymphocytes & 2950 & 1134 & 3414 & 216 & 320 & 972 & $1000-4000$ \\
Monocytes & 295 & 567 & 2276 & 0 & 160 & 486 & $150-1200$ \\
Eosinophils & 885 & 567 & 1138 & 108 & 960 & 162 & $0-1500$ \\
Basophils & 0 & 0 & 0 & 0 & 0 & 0 & $0-50$ \\
ALT & 11.90 & 17.0 & 65.6 & - & 74.0 & 20.0 & $10-109$ \\
FA & 134.40 & 93.0 & 326.4 & - & 348.0 & 195.0 & $1-114$ \\
Urea & 27.20 & 26.2 & 24.2 & - & 15.0 & 11.0 & $8-28$ \\
Creatinine & 0.9 & 0.5 & 0.6 & - & 0.6 & 0.7 & $0.5-1.7$ \\
Albumin & 1.60 & 1.7 & 1.9 & - & 2.0 & 1.8 & $2.3-3.1$ \\
\hline
\end{tabular}

* Prescribed HU at dose of $18 \mathrm{mg} / \mathrm{kg}$ PO SID.

** 35 days after treatment of HU. Interruption of HU treatment and prescription of chlorambucil at dose of $6 \mathrm{mg} /$ $\mathrm{m}^{2}$ PO SID and prednisone $1 \mathrm{mg} / \mathrm{kg}$ PO SID.

*** 10 days after chlorambucil cyclophosphamide was started at dose of $300 \mathrm{mg} / \mathrm{m}^{2}$ once, then $250 \mathrm{mg} / \mathrm{m}^{2}$ every 21 days, for one year.

One limitation of this case report is the unavailability of a histopathology exam. A histopathology of claw biopsies would have provided evidence of whether the claw lesions were secondary to hydroxyurea toxicity. Such an exam would have been important not only for obtaining a more accurate diagnosis of the claw lesions but also for ruling out other possible causes of onychodystrophy, such as lupoid onychodystrophy. The association between the claw lesions and chemotherapy detected here is based solely on the clinical observation that the lesions appeared temporally with the initiation of hydroxyurea and resolved after its discontinuation.
One study in African children with sickle-anemia treated with hydroxyurea noted the development of ungual alterations in three children after 6-8 weeks of use, which were mainly manifested as ungual hyperpigmentation, longitudinal bands in nails and macular hyperpigmentation. ${ }^{21}$ The authors of that study suggested that the cutaneous side effects of hydroxyurea may be influenced by ethnicity and pigmentation. Accordingly, it is possible that cutaneous side effects of hydroxyurea may be related to breed predisposition or pigmentation in dogs. Few studies describing onycholysis induced by chemotherapy exist in the veterinary literature. The fact that the

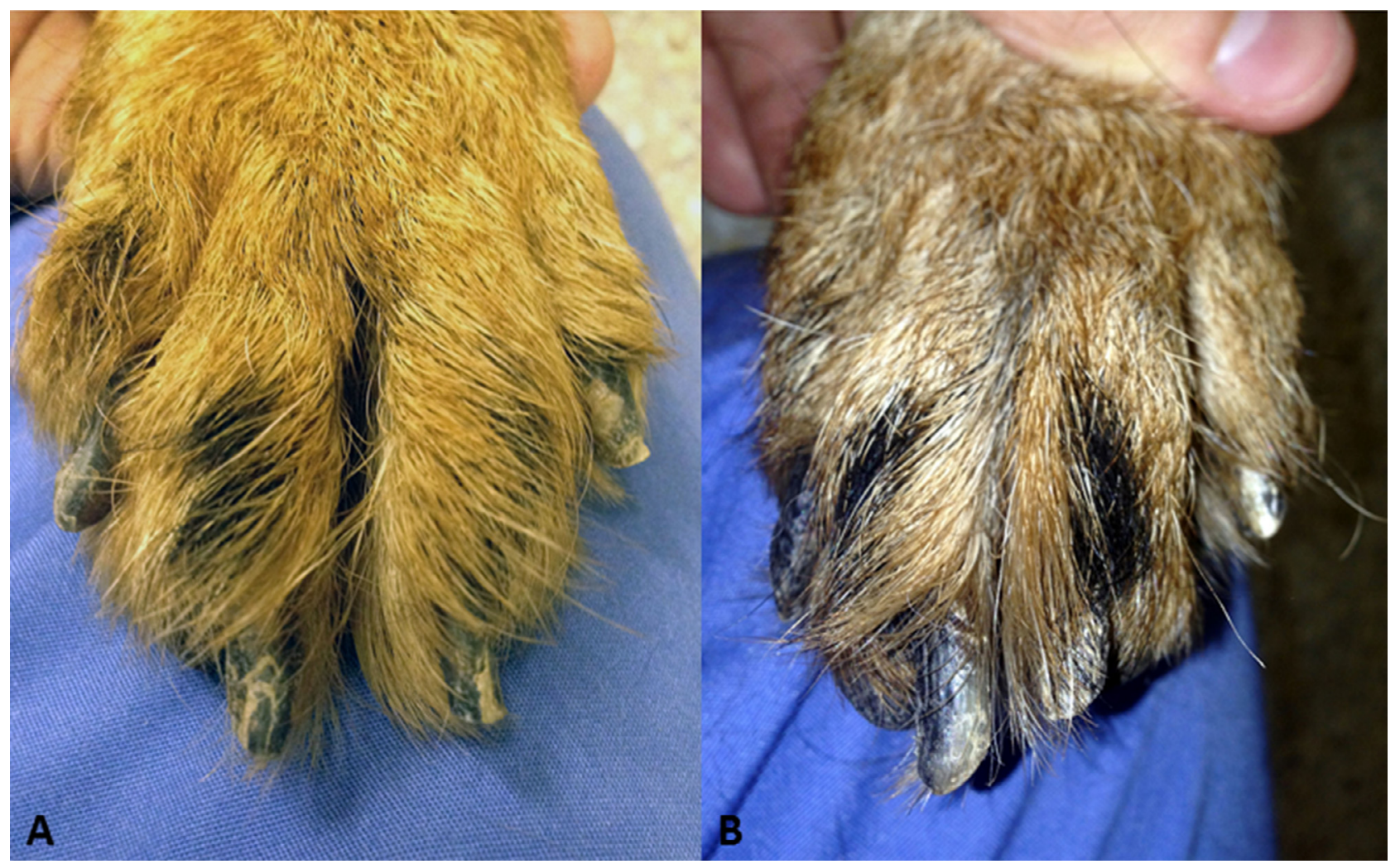

Fig. 2. Healing of onycholysis involving the pelvic (A) and thoracic (B) left limbs three months after hydroxyurea was discontinued. 
patient in this study had pigmented skin associated with the development of cutaneous side effects at a therapeutic dose suggest the possible influence of pigmentation. Further studies are required to investigate the potential role of pigmentation in the development of onycholysis after hydroxyurea treatment in veterinary patients.

\section{Conclusions}

To the authors' knowledge, this is the first report of hydroxyureainduced onycholysis within a short-term period in a dog. Clinicians should be aware of this potential unusual adverse effect when using hydroxyurea.

\section{References}

1. Marconato UB L, Fileccia I. Unusual dermatological toxicity of hydroxyurea in two dogs with spontaneously occurring tumours. J Small Anim Pract 48:514-517.

2. Gustafson DL PR. Cancer chemotherapy. Small Animal Clinical Oncology; 2013. p. 5th edition 157-173.

3. Moore KW SR. Hydroxyurea for treatment of polycythemia secondary to right-toleft shunting patent ductus arteriosus in 4 dogs. J Vet Intern Med 15:418-421.

4. Fine DM TH. Chronic granulocytic leukemia in a dog. J Am Vet Med Assoc 214:1809.

5. vLM Favier RP, E Teske. Essential thrombocythaemia in two dogs. Tijdschr Diergeneeskd 129:360-364.

6. Perkins MC WA. Successful treatment of hypereosinophilic syndrome in a dog. Aust Vet J 79:686-689.

7. Rassnick KM A-SR, Bailey DB, Chretin JD, Phillips B, Zwhalen CH. Phase II openlabel study of single-agent hydroxyurea for treatment of mast cell tumours in dogs. J Vet Comp Oncol 8:103-111.

8. Hae-Won JUNG H-CL, Ji-Hyun KIM, Hyo-Mi JANG, Jong-Hyun MOON Jung-Hyang SUR, Jeongim HA. Dong-In JUNG: Imatinib Mesylate plus Hydroxyurea Chemotherapy for Cerebellar Meningioma in a Belgian Malinois Dog. J Vet Med Sci 76:1545-1548.

9. SJB Erica LLiebelt, Faber Willem, Fisher Jeffrey W, Hughes Claude L, Lanzkron Sophie M, Lewis Kerry M, Marchetti Francesco, Mehendale Harihara M, Rogers John M, Shad Aziza T, Skalko Richard G, Stanek Edward J. NTP-CERHR Expert Panel
Report on the Reproductive and Developmental Toxicity of Hydroxyurea. Birth Defects Res (Part B) 80:259-366.

10. Charache S, Terrin ML, Moore RD, Dover GJ, Barton FB, Eckert SV, McMahon RP, Bonds DR. Effect of hydroxyurea on the frequency of painful crises in stickle cell anemia. N Engl J Med 332:1317-1322.

11. Food and Drug Administration CfDEaR: Droxia (hydroxyurea capsules, USP). Accessed May 02, 2016.

12. MAGT Emmanuel Rodrigues de França, Matias Kleber de Freitas, Morais Antunes Daniela Eugenia Costa, Braz Rafael de Almeida, Silva Claudia Elise Ferraz. Cutaneous effects after prolongaded use of hydroxyurea in polycythemia vera. An Bras Dermatol 86:751-754.

13. Vassalo C PF, Merante S, Ardigò M, Nolli G, Mangiacavalli S, Borroni G. Muco-cutaneous changes during long-term therapy with hydroxyurea in chronic myeloid leukaemia. Clin Exp Dermatol 26:141-148.

14. Harminder S Sandhu PJB, Hernandez Paul. Hydroxyurea-induced hypersensitivity pneumonitis: a case report and literature review. Can Resp 7:491.

15. Group VCO. Veterinary cooperative oncology group - common terminology criteria for adverse events (VCOG-CTCAE) following chemotherapy or biological antineoplastic therapy in dogs and cats v1.0. J Vet Comp Oncol 2:194-213.

16. Young KM, Vail DM. Canine acute myeloid leukemia, myeloproliferative neoplasms, and myelodysplasia. Small Animal Clinical Oncology; 2013. p. 5th edition 653-662.

17. Morton D RL, Huang W, Marcek JM, Austin-LaFrance R, Northcott CA, Schelling SH Enerson BE, Tomlinson L. Toxicity of hydroxyurea in rats and dogs. Toxicol Patho 43:498-512.

18. Florence Aslinia JJM, Steven H. Yale: megaloblastic anemia and other causes of macrocytosis. Clin Med Res 4:236-241.

19. Juopperi TA BD, Bernreuter DC, Vernau W, Thrall MA, McManus PM. Prognostic markers for myeloid neoplasms: a comparative review of the literature and goals for future investigation. Vet Pathol 48:2011.

20. NHAA Kendra LSweet, Komrokji Rami S, Lancet Jeffrey E. Javier Pinilla-Ibarz: macrocytosis and iron stores in patients with chronic myeloid leukemia being treated with tyrosine kinase inhibitors 54th ASH Annual Meeting and ExpositionAvailable in 2012. https://ash.confex.com/ash/2012/webprogram/Paper46624.html.

21. O'branski EE WR, Prose NS, Kinney TR. Skin and nail changes in children with sickle cell anemia receiving hydroxyurea therapy. J Am Acad Dermatol 44:859-861.

22. Gauthier O GJ. Bret-Dibat C: Atrophie cutanée collodionnée au cours de traitements prolongés par hydroxyurée $=$ Atrophic collodion skin in long-term treatment with hydroxyurea.. An dermatol et de vénéréologie 123:727-731. 